\title{
MODELING AND PREDICTION OF WEAR RATE OF ALUMINUM ALLOY (Al 7075) USING POWER LAW AND ANN
}

\author{
Mohammad Hanief*, Shafi M. Charoo \\ National Institute of Technology Srinagar, Jammu \& Kashmir, 190006, India
}

Received 04.08.2020

Accepted 01.09.2020

\begin{abstract}
The wear process significantly influences machine partsduring their useful life. The wear process is complex, and therefore, it is very difficult to develop a comprehensive model involving all the operating parameters. In the present study, wear rate is measured during the wear process at different operating parameters such as force (load), sliding distance, and velocity. Power lawand Artificial neural network (ANN) approaches are used to model the wear rate of Al7075alloy. Power law and neural network-based models are compared using statistical methods with a coefficient of determination $\left(\mathrm{R}^{2}\right)$, mean absolute percentage error (MAPE), and means square error (MSE). It is seen that the proposed models are competent to predict the wear rate of Al7075 alloy. The ANN model estimates the wear rate with high accuracy compared to that of the power lawmodel. The models developed for wear rate were found to be consistent with the experimental data.ANOVA analysis revealed that the load hasa significant effect on the wear rate than the sliding speed and sliding distance.
\end{abstract}

Keywords: ANN; Al7075Alloy; wear rate; model.

\section{Introduction}

Aluminum alloy 7075 is widely used in several fields, e.g., automotive, marine, aerospace, equipment etc. Surface deteriorations are impediments to the longevity of aluminum components. Surface mechanical attrition, which includes high-pressure torsion and laser shot peening, [1-4], high energy shot peening and surface burnishing etc., are among the several methods to strengthen the surface [1].Tribological behavior reveals a direct relation of wear rate with the load and, while inverse relation with the sliding distance [5]. The wear rate of Aluminum metal matrix composites (AMMCs) is lower compared to base alloy increased graphite reinforcement. The base alloy is softer than reinforced composites, which results ina higher wear rate due to plastic deformation $[6,7]$. Modeling of wear constitutes an important component to study the wear 
phenomenon. Several modeling techniques have been used for modeling and optimization of wear, which include regression, ANN. The ANN application in the field of tribology has attracted the increasing interest of the researchers $[8,9]$. The main reason is that analytical and computational modeling is difficult to use for tribological phenomena, which are highly nonlinear in nature [10]. Apparently, Jones et al. [11] were the first to predict tribological properties using a limited set of experimental data.

The ANN procedure has been used to estimate the $\mathrm{Al} / \mathrm{Al}_{2} \mathrm{O}_{3}$ metal matrix composites wear rate. Also, the online application of ANN for estimation of wear of cutting tools during machining has been reported in the literature $[12,13]$. Taguchi's method and genetic algorithm (GA) have been used to study the MMC and optimization of wear parameters [14]. The abrasive wear behavior of Aluminum MMC during the machining process using the regression method and GA for optimization of inputs has also been reported $[15,16]$. An exhaustive literature reviewabout the application of ANN as a modeling technique has been reported in the review paper [17]. It reports the application of ANN in tribological studies in detail.

It is evident from the literature survey that although significant work has been reported for modeling and optimization of the wear process. But there is a scope of ANN and regression analysis to investigate the wear processfor modeling and optimization, particularly composite materials. The present work aims to study the influence of operating parameters on the wear of aluminum alloy7075 using regression and ANN.

\section{Methods and Materials}

\section{Power law model}

The power law model for wear rate can be demonstrated in terms of the input parameters i.e., sliding velocity $(v)$, sliding distance $(s)$, and force $(f)$.

$$
w=k v^{a} s^{b} f^{c}
$$

where $w$ the wear is the rate, and $a, b$, andc are unknown constants, to be determined from the experimental data. Eq (1) can be linearized by logarithmic transformation to determine the constants. We get

$$
\ln (w)=\ln (k)+a \times \ln (v)+b \times \ln (s)+c \times \ln (f)
$$

Equation (2) is rearranged as a linear mathematical model and is given as Eq. (3)

$W=K+a V+b S+c F$

where $\quad W=\ln (w), K=\ln (k), S=\ln (s), \quad V=\ln (v), \quad F=\ln (f)$

using least square to determine constants, we use

$\left.\mu=\left(X^{T} \cdot X\right)^{-1} \cdot X^{T} \cdot W\right)$

The coefficients in Eq. (4) are obtained from the experimental data, where

$$
\mu=\left[\begin{array}{l}
K \\
a \\
b \\
c
\end{array}\right]
$$




$$
X=\left[\begin{array}{ccc}
v_{1} & f_{1} & s_{1} \\
v_{2} & f_{2} & s_{2} \\
. . & . . & . . \\
. . & . . & . . \\
v_{n} & f_{n} & s_{n}
\end{array}\right]
$$

\section{ANN model}

The ability of ANN to solve nonlinear problems has drawn the attention of the researchers to address the problems of machining. So, it has been used in this work too. ANN has many layers that depend on the complexity and type of problem. Generally, ANN has three layers, i.e., input, hidden, and output layer. The inputs are fed at the input layer and processed next in the hidden layer. The output is computed in the hidden layer, and final results are produced after processing in the output layer. The hidden and the output layer compute results based on the transfer functions. In this work, tansig and purelin functions were used as transfer functions in the hidden and output layers, respectively, given in Eqs. (7a) and (7b). The ANN model is shown schematically in Figure 1.

$$
\begin{aligned}
& F(x)=\frac{e^{x}-e^{-x}}{e^{x}+e^{-x}} \\
& F(x)=x
\end{aligned}
$$

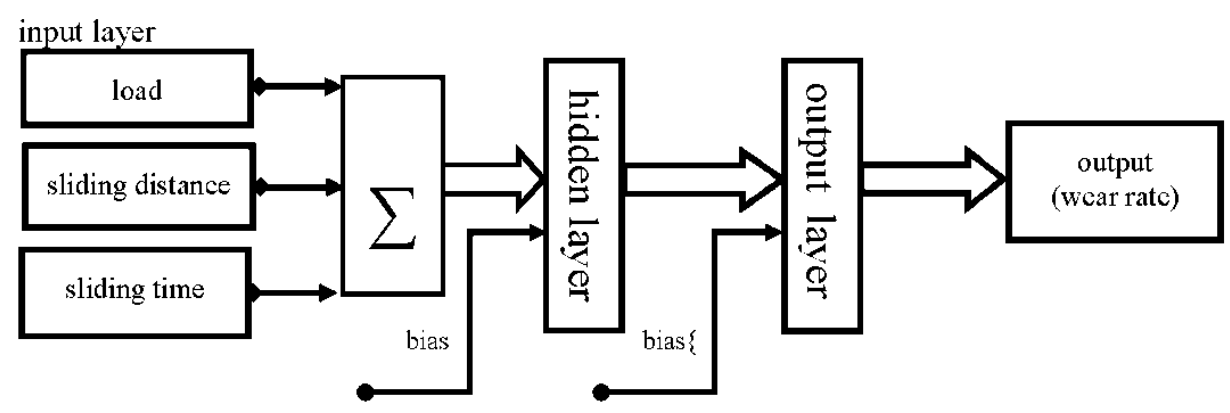

Fig. 1.Schematic of ANN used for the modeling.

The ANN is initiated by training, where the input, along with the output, is introduced to the network, and the weights are randomly set. To achieve a satisfactory performance level, a backpropagation algorithm is used to minimize the MSE, by altering weight. In the backpropagation algorithm technique, the weights are adjusted by propagating changes in weights back to the input neuron from the output neuron [18].The training process is stopped at the attainment of a satisfactory level of performance. The network generated thereof uses the weights to make the decisions. In this paper ANN model was developed using MATLAB toolbox. The parameters used for the network are given in Table 1. 
To arrive at the best possible solution, several runs with different initial weights were chosen independently. The MSE of the learning process of the network was evaluated by

$$
M S E=\frac{\sum_{N}^{i=1}\left(T_{i}-O_{i}\right)^{2}}{N}
$$

Table 1. Network parameters used for training.

\begin{tabular}{ll}
\hline Number of neurons on the layer & Input: 1 hidden:2 output: 1 \\
Initial weights and biases & Randomly between -1 and 1 \\
Activation function & Tansig \\
Rate of Learning & 0.05 \\
Momentum constant & 0.95 \\
Epoch & 1000 \\
\hline
\end{tabular}

where $T$ and $O$ are target and output values, respectively. The weights are again adjusted between the hidden and output layer and are calculated by Eq. (9).

$$
\Delta w_{j i}(n)-\alpha \Delta w_{j i}(n-1)+\eta \delta_{j}(n) y_{i}(n)
$$

where $\Delta w_{j i}(n)$ is the weight change, $\alpha$ the momentum coefficient, $\delta_{j}(n)$ error, $\eta$ learning rate, and $y_{i}(n)$ is the output. The ANN outputs were tested with the experimental results and were not presented during the network training process after successful training. The results were again compared with using $\mathrm{R}^{2}$ and MSE. $\mathrm{R}^{2}$ is defined as the proportion of the variance in the variable (dependent) that is predicted from the independent variable and is given by

$$
R^{2}=1-\left(\frac{\sum_{i=1}^{N}\left(T_{i}-O_{i}\right)^{2}}{\sum_{i=1}^{N}\left(O_{i}\right)^{2}}\right)
$$

\section{Results and discussion}

Power law was used for modeling wear rate in terms of sliding velocity, sliding distance, and load. The model parameters of the power law equation were determined from experimental data adopted from Prabha et al. [19]. The model thus obtained is given by Eq. (11)

$$
w=12.673 v^{0.0396} f^{0.3918} s^{-0.0065}
$$

The proposed model is similar to Archard-Kragelsky model [19] and has been applied in the ANN wear model recently [20].The Archard-Kragelsky model assumes nonlinear dependence of wear rate on contact pressure and velocity. However, recently the sliding distance was included in the model [21] using ANN.

The process levels of wear process chosen for this study are presented in Table 2.

Table 2.Levels of process parameters. 


\begin{tabular}{lccc}
\hline Parameter & Level-1 & Level-2 & Level-3 \\
\hline Sliding velocity $(\mathrm{m} / \mathrm{sec})$ & 1 & 1.5 & 2 \\
Sliding distance $(\mathrm{m})$ & 200 & 350 & 500 \\
Force $(\mathrm{N})$ & 10 & 15 & 20 \\
\hline
\end{tabular}

The output, as shown in Figure 2 and Figure 3, is compared with the experimental results on the basis of statistical parameters $\mathrm{R}^{2}$, MSE, and MAPE, to evaluate the competence of the proposed model. The $\mathrm{R}^{2}$, MSE, and MAPE were found to be $99.96 \%$, 0.48817 , and 0.014704 , respectively. Also, the developedmodel is significant as the $\mathrm{P}$ values were found to be less than 0.05 . The results indicate that the proposed model is competent to predict the value of wear rate with appreciable accuracy for the given inputs. For the given inputs between and outside the above range, the wear rate can be predicted with appreciable accuracy, i.e., the wear rate can be extrapolated beyond the velocity of $2 \mathrm{~m} / \mathrm{sec}$, sliding distance $500 \mathrm{~m}$, and force of $20 \mathrm{~N}$.

Table 3.ANOVA Results.

\begin{tabular}{llllll}
\hline & $d f$ & $S S$ & $M S$ & $F$ & Significance $F$ \\
\cline { 2 - 6 } Regression & 3 & 0.062912 & 0.020971 & 242.3096 & $1.5399 \times 10^{-17}$ \\
Residual & 23 & 0.001991 & $8.65 \mathrm{E}-05$ & & \\
Total & 26 & 0.064903 & & & \\
\hline
\end{tabular}

To determine the dependency of the wear rate on the operating parameters, the ANOVA test was used at a confidence level of $95 \%$ with a significance level less than 0.05 . The results of ANOVA analysis are shown in Table 3; the significance level is well below 0.05.It can be inferred from the ANOVA analysis that the load influences the wear rate significantly as compared to the sliding velocity (v) and sliding distance (s). Also, form Eq. (11) $(\partial w / \partial v)>0,(\partial w / \partial f)>0$ and $(\partial w / \partial f)<0$, which implies that the wear rate increases with velocity and load while the wear rate decreases with an increase in sliding distance. 


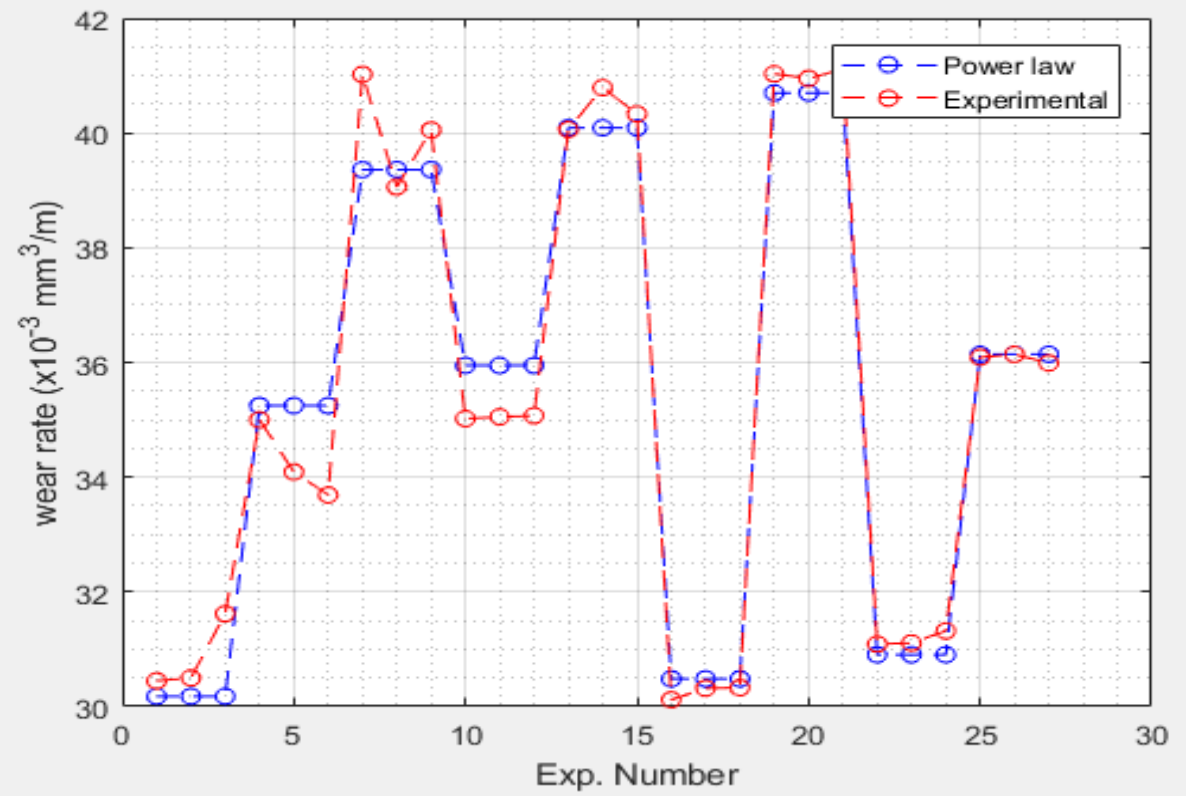

Fig. 2. Comparison of power law and Experimental results.

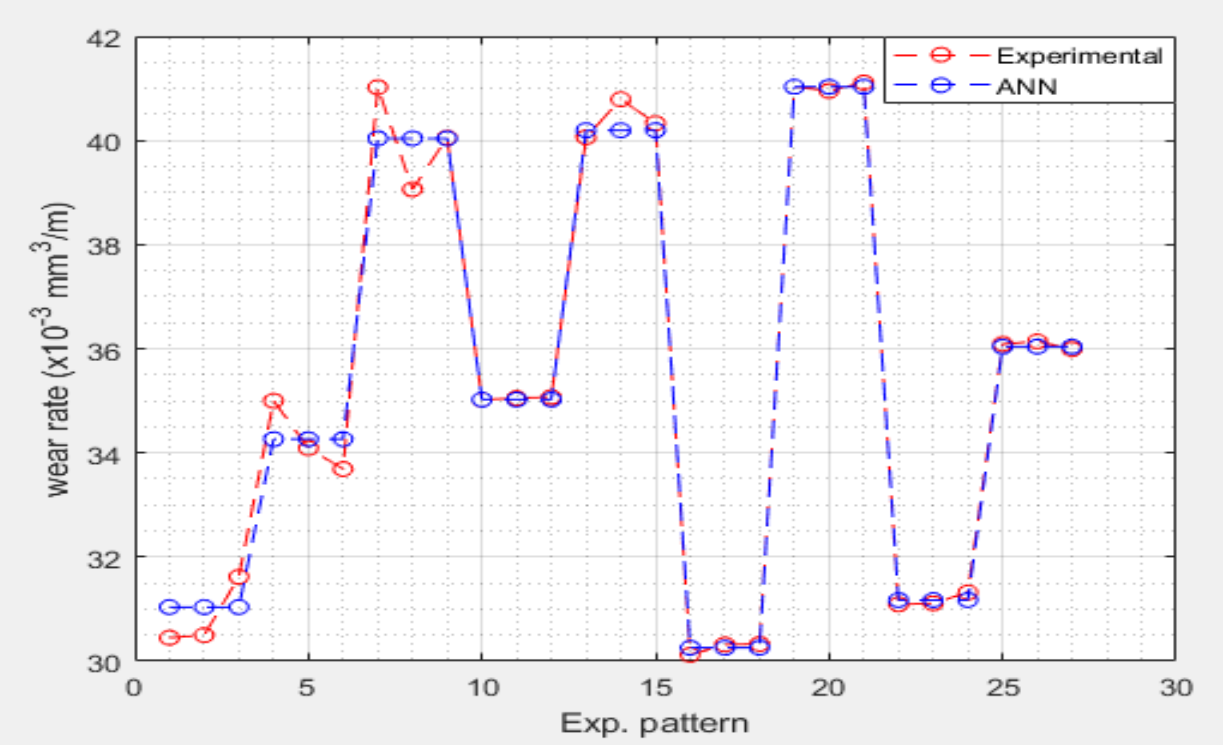

Fig. 3. Comparison of ANN and experimental results.

The network was trained for 17 experimental data points values for developing an ANN model, the. The network was successfully trained. The network was used for prediction of the wear rate for testing and validation. The ANN results shown in Fig. 5. indicate clearly that experimental data and predicted values perfectly lie on the regression 
line during training, which gives the $\mathrm{R}^{2}=0.99373$. The $\mathrm{R}^{2}$ for testing and validation were 0.99795 and 0.99992 , respectively. The training was stopped at this stage, and all the experimental values were used. The overall $\mathrm{R}^{2}$ was found to be 0.99519 .

From Figure 4 (i), (ii) and (iii) at the load of 10, 15, and $20 \mathrm{~N}$ respectively, the wear rate changes (increases) significantly with the velocity and changes (decreases) very feebly with the sliding distance. The wear rate decreases largely with the load at a constant sliding distance of 200,300, and 400m as compared with the velocity, as can be seen from the Figure 4 (iv), (v), and (vi). Similarly, from Figure4 (vii), (viii) and (ix) for the constant velocity of $1,1.5$, and $2 \mathrm{~m} / \mathrm{sec}$, the respective changes in wear rate with load is greater than the change with the sliding distance.

(i)

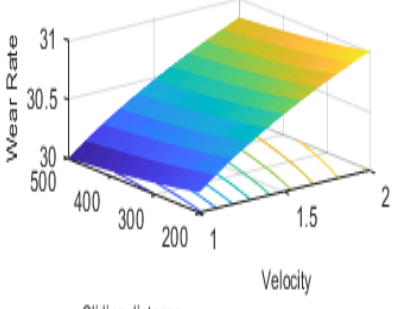

Siling distance

(iv)

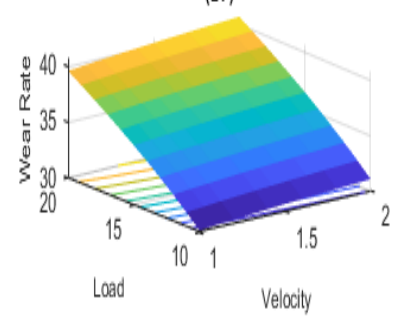

(vii)

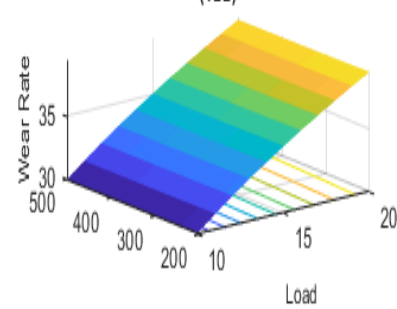

Silding distance (ii)

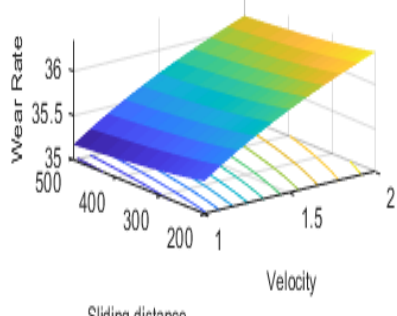

Siling distance

(v)

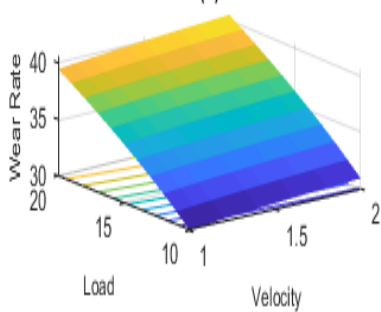

(viii)

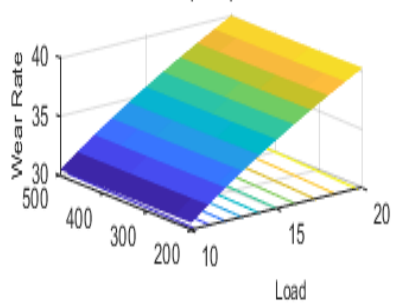

Siding distance (iii)

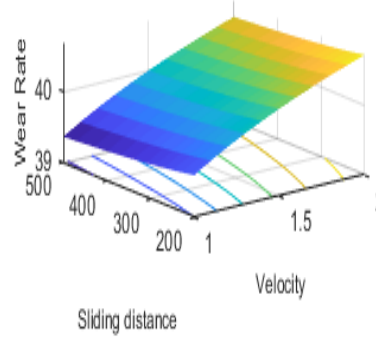

(vi)

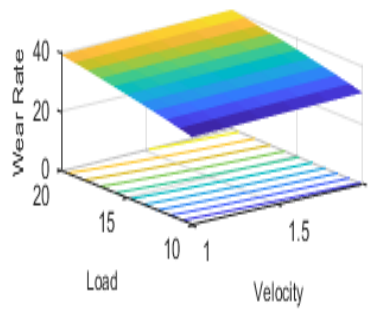

(ix)

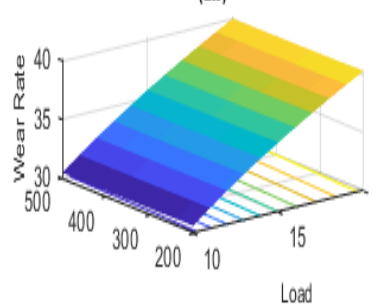

Siling distance

Fig. 4. Variation of wear rate with operating parameters. 

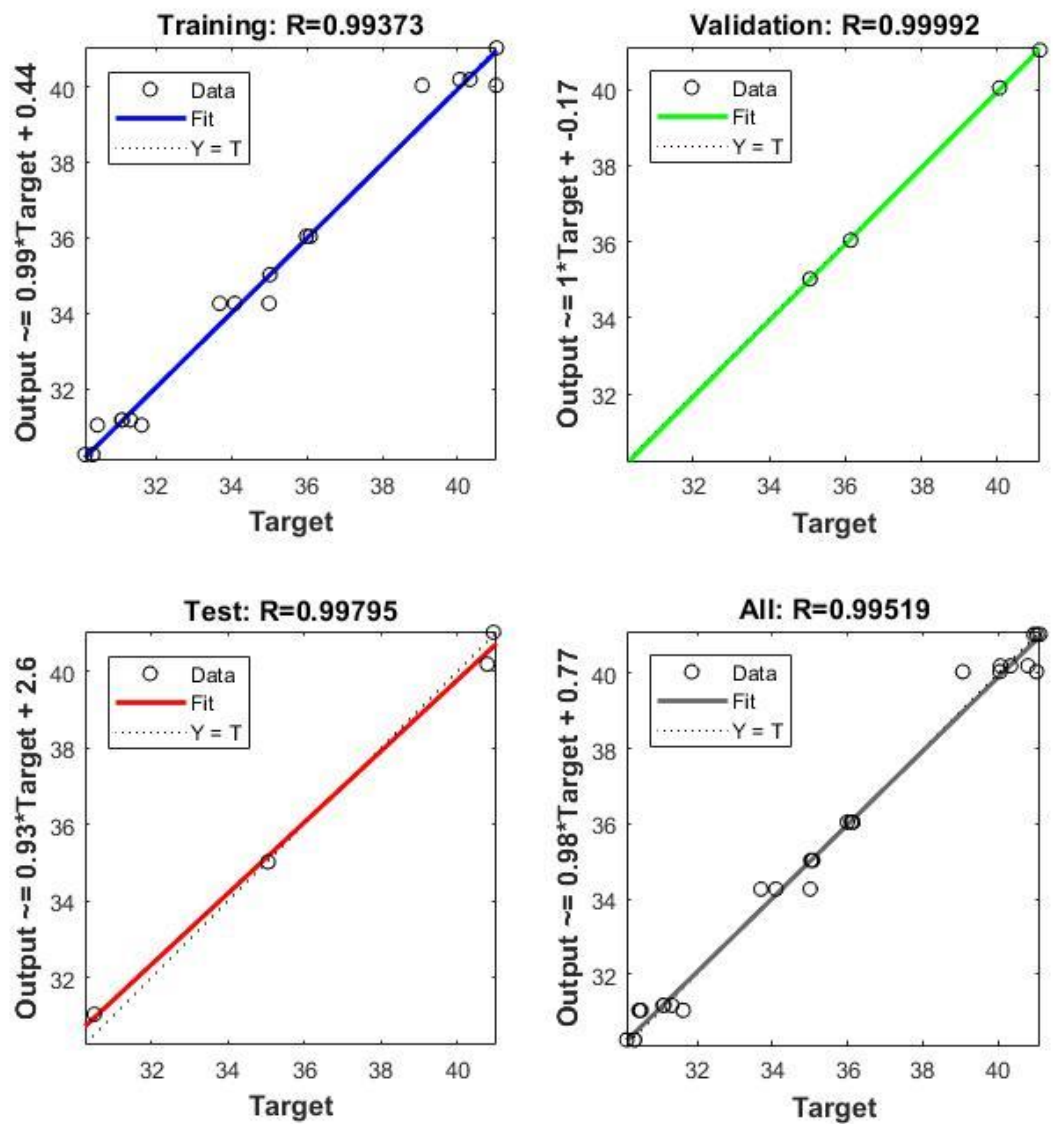

Fig.5.ANN model-correlation of parameters for wear rate.

\section{Conclusion}

The models for wear rate, during the sliding of Al 7075 are obtained using power law and ANN in this work. The effect of inputs on the wear rate has been analyzed by employing proposed models. The competence of the models developed was determined by ANOVA, and the following inferences were drawn.

1. $R^{2}$ of the power law model was found to be $99.83 \%$ and that of ANN model, $99.51 \%$, respectively. It is concluded that the proposed models are competent to predict the wear rate.

2. The wear rate increased with sliding velocity, while load decreased with the increase in sliding distance.

The load has a significant influence on the wear rate followed by the siding velocity and sliding distance 


\section{References}

[1] M. Sato, N. Tsuji, Y. Minaminob, Y. Koizumi: Science and Technology of Advanced Materials, 5 (2004) 145-152.

[2] L. Hackel, J. R. Rankin, A. Rubenchik, W. E. King, M. Matthews: Additive Manufacturing, 24 (2018) 67-75.

[3] B. B. Straumal, A. R. Kilmametov, O. A. Kogtenkova, A. A. Mazilkin, B. Baretzky, A. Korneva, P. Zięba: International Journal of Materials Research, 110 (2019) 608-613.

[4] K. Wu, Y. Xinjian, H. Zhan, W. Haodong, L. Ting, Y. Zhe, L. Jun: Journal of Materials Engineering and Performance, 28 (2019) 2937-2945.

[5] N. S. Prabhakar, N. Radhika, R. Raghu: Procedia Engineering, 97 (2014) 9941003.

[6] G. B. Narasimha, M. V. Krishna, R. Sindhu: Procedia Engineering, 97 (2014) 555-562.

[7] A. Baradeswaran, A. Elayaperumal, R. F. Issac: Procedia Engineering, 64 (2013) 973-982.

[8] L. Haviez, R. Toscano, M. El Youssef, S. Fouvry, G. Yantio, G. Moreau: Journal of Intelligent \& Fuzzy Systems, 28 (2015) 1745-1753.

[9] D. Li, R. Lv, G. Si, Y. You: Polymer Composites, 38 (2017) 1705-1711.

[10] K. Velten, R. Reinicke, K. Friedrich: Tribology International, 33 (2000) 731-736.

[11] S. P. Jones, R. Jansen, R. L. Fusaro: Tribology Transactions, 40 (1997) 312-320.

[12] T. Mahmoud: Artificial neural network prediction of the wear rate of powder metallurgy Al/Al2O3 metal matrix composites, Proceedings of the Institution of Mechanical Engineers, Part L: Journal of Materials: Design and Applications, 226 (2012) 3-15.

[13] A. Ghasempoor, T. Moore, J. Jeswiet: Online wear estimation using neural networks, Proceedings of the Institution of Mechanical Engineers, Part B: Journal of Engineering Manufacture, 212 (1998) 105-112.

[14] N. M. Kumar, S. S. Kumaran, L. Kumaraswamidhas: Alexandria Engineering Journal, 55 (2016) 19-36.

[15] N. Radhika, K. Vijaykarthik, P. Shivaram: Journal of Engineering Science and Technology, 10 (2015) 258-268.

[16] X. Chen, L. Ma, C. Li, X. Cao: The International Journal of Advanced Manufacturing Technology, 74 ( 2014) 207-217.

[17] I Argatov: Frontiers in Mechanical Engineering, 5 (2019) 1-9.

[18] A. M. Zain, H. Haron, S. Sharif: Expert Systems with Applications, 37 (2010) 4650-4659.

[19] N. R. Prabha, J. E. R. Dhas: In: Proceedings ICCICCT. Eds.: Curran, IEEE 2016, p. $750-753$.

[20] I Argatov, Young S Chai: Tribology International, 138 (2019) 211-214.

[21] I Argatov, Young S Chai: Artificial neural network modeling of sliding wear, Proceedings of the Institution of Mechanical Engineers, Part J: Journal of Engineering Tribology (2020) 1-10.

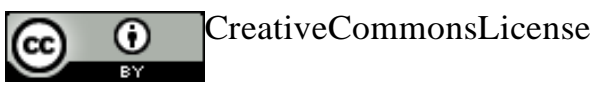

This work is licensed under a Creative Commons Attribution 4.0 International License. 